\title{
CONFERENCE REPORT: \\ OPPORTUNITY AND CHALLENGE IN WOOD DRYING: QUALITY CONTROL AND ENERGY SAVING
}

\author{
Dr Shusheng Pang ${ }^{1}$, Professor Lianbai Gu ${ }^{2}$
}

The $9^{\text {th }}$ IUFRO (International Union of Forestry Organisation) International Wood Drying Conference was held in August 21-26, 2005, in Nanjing, China. It attracted over 120 from 24 countries. At the conference, 58 papers were orally presented and 31 papers were presented as posters. This conference was another success following the eight previous conferences held, respectively, in Skelleftea (Sweden) in 1987, Seattle (USA) in 1999, Vienna (Austria) in 1992, Rotorua (New Zealand) in 1994, Quebec (Canada) in 1996, Stellenbosch (South Africa) in 1999, Tsukuba (Japan) in 2001 and Brasov (Romania) in 2003 .

The papers presented at the $9^{\text {th }}$ IUFRO International Wood Drying Conference reflected the latest progresses and achievements in wood drying research and development. These papers covered fundamental research (heat and mass transfer, stress development and modelling), new technology development (microwave/radio frequency drying, vacuum drying) and drying related wood properties. The highlight was the research on quality control and energy saving which was the theme of the conference and attracted 14 papers orally presented.

Wood drying is a key operation in wood processing on the bases that many wood product problems are related to drying and drying consumes large amount of energy. Drying defects such as distortion, residual drying stress, checking, discolouration and non-uniform moisture content after drying have been concerns and cause significant economic loss for the wood processors. However, these drying problems are, in most cases, related to intrinsic wood properties and thus for quality control, an integration approach is needed across the processing chain from raw material, wood sawing, through wood drying to remanufacturing. We are pleased to note these issues were addressed in the papers presented and hope this trend will continue in the future.

Energy consumption and environmental impact of wood drying is another area which attracted great attention from researchers. People are more and more aware of the consequences of commercial activities on our living environment. With the potential shortage of energy supply and negative impact of using fossil fuels, there are great opportunities to increase the energy efficiency and to use renewable energy resources for the wood drying.

All of the papers presented at the $9^{\text {th }}$ IUFRO International Wood Drying Conference can be found in the conference proceedings (iufrowdc@njfu.edu.cn).. A selecting papers has been arranged for publication in a special issue of Drying Technology and Maderas. Ciencia y tecnología.

We are most thankful to Professor Rubén A. Ananías, the editor of Maderas. Ciencia y tecnología, for his great efforts and help to publish this special issue which papers were selected from this conference. However, these papers have been updated with new progresses and new results focusing on drying related wood properties and drying quality.

\footnotetext{
${ }^{1}$ Associate Professor and Director, Wood Technology Research Centre, Department of Chemical and Process Engineering, University of Canterbury, Christchurch, New Zealand. E-mail: shusheng.pang@canterbury.ac.nz

${ }^{2}$ Professor and Director of Wood Drying Lab, Nanjing Forestry University, Nanjing 210037, China. E-mail: dugx@xinandrying.com
} 
The next IUFRO International Wood Drying Conference will be held in late August, 2007, in campus of the University of Maine in Orono, USA. Further information can be obtained from Professor Michael Milota, Oregon State University (mike.milota@oregonstate.edu), or Professor Bob Rice of the University of Maine (Robert_Rice@umit.maine.edu). 